Murmurations:

Journal of

Transformative

Systemic

Practice

\title{
Therapy in Unsettling Times
}

\author{
Marilena Karamatsouki
}

\section{Volume 2}

Issue 2

Winter 2019

Keywords:

systemic therapy,

self-reflexivity,

relational

reflexivity, stories,

relational ethics,

new materialism

Citation Link

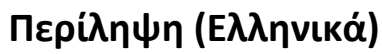

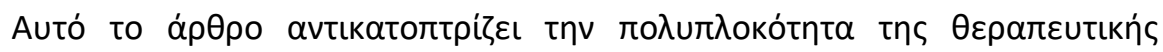

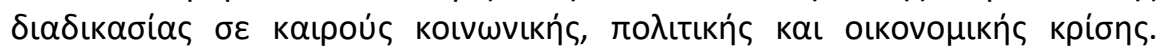

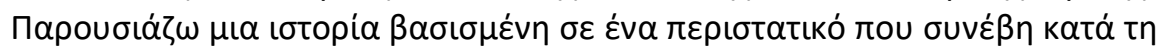

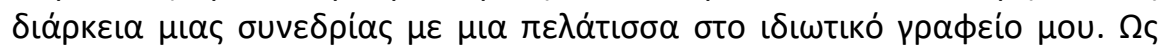

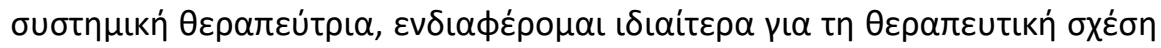

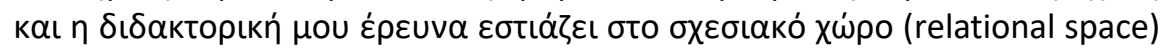

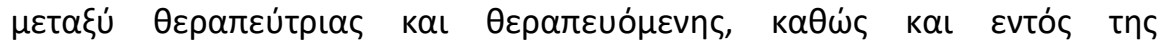

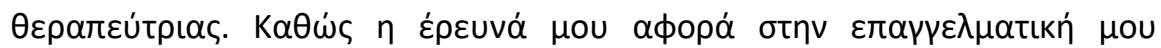

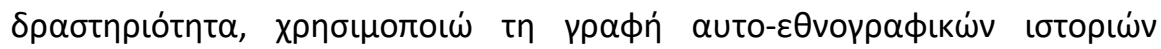

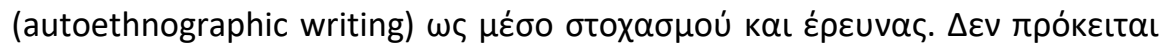

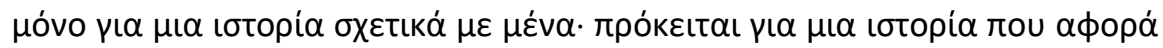

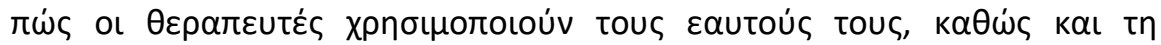

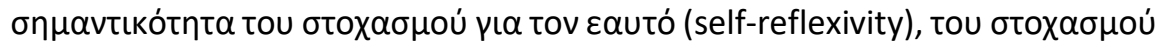

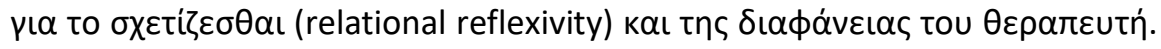

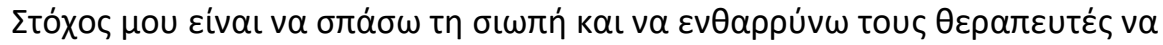

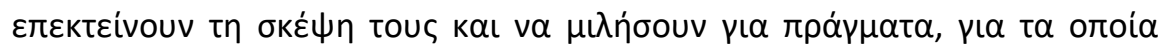

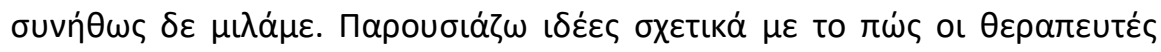

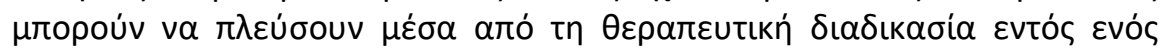

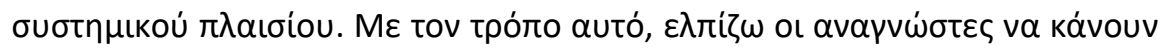

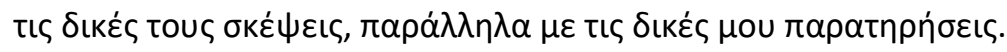


"The more of me that is in the therapy room, the more of the client could be in there too."

(Etherington 2004, p.58)

"So, as we wrap up the session for today, can I ask you for some feedback? What are some of your thoughts? What are your feelings? What did you find useful in today's session, if any?", I ask my client Bella.

Asking clients for feedback at the end of the session is something I often do in my work as a systemic therapist. During the years I have been practising, I have found it useful to take a "not-knowing" position (Anderson 2005) and provide a framework where the client and I become co-responsible in creating a new story for their lives (Oliver 2014).

"Oh, I am feeling much more relaxed now", Bella responds. "When I came in today, I didn't really know what to say or think. I am still in a confusion, but after everything we talked about today, I feel less fearful of exploring this uncertainty I am feeling", she continues.

"Good", I reply with a smile. "You are in a perfect place." I think about this young woman's journey in therapy so far and I am really pleased and proud of the therapeutic work we are doing together. We have created a strong therapeutic alliance from early on and in the relational space between us we continually evolve in each other's presence (Hendrix and Hunt 2017).

I am about to stand up, indicating the session is over, when I sense that Bella is hesitating, as if there is something else she wants to say. I look at her puzzled.

"Can I ask you...", she starts saying. "How are you doing? You look... tired today."

I feel like someone slapped me in the face. Thoughts start rushing through my mind:

Is it that obvious? What should I say to her? What if she thinks I am not doing a good job? Am I doing a good job? Maybe I need to take a break with all these things I am going through at the moment. If I take a break, how am I supposed to make a living? Things are bad in terms of finances as it is... I have to tell her something! What should I do?

The truth is I am tired. During the last two months I am dealing with a situation that leaves me exhausted and drained of energy. The social, political and economic situation in the country where I live and practise is getting worse and worse every day and this affects everybody. Therapists, like myself, are trying to balance trying to maintain a profession and at the same time be a resource in the therapeutic practice. In particular, I was working two and a half days a week in a centre which provided therapy for children with special needs. Due to increased taxes and cuts in funding from the governmental budget, however, my business partner and I made the tough decision to close down the centre after twelve years. And this happened only last month. So, during these last few weeks I have been dealing with informing the families I am working with, some of whom I know for more than ten years, and to prepare some kind of closure for all of us, therapists and clients. This process included a lot of tears, anger, sadness, frustration... Packing twelve years of practice into cardboard boxes is no easy task... 
I suddenly return my thoughts to the here-and-now as I realise I have a client sitting in front of me, worrying about me and waiting anxiously for an answer. My inner dialogue, my thoughts, feelings and experiences that I bring in the session, are also important in the therapeutic encounter. I am reminded of how Rober (2010) uses the therapist's inner conversation in the therapy session, but I am also bringing honesty in the therapy room in responding to client's questions. I have always been a proponent for the therapist's openness and transparency, which I have found can be beneficial to clients, when done carefully and skilfully. However, I also have to be aware of the impact my reflections have on the therapy process. I sit straight in my chair and take a deep breath.

"Well...", I hear myself saying, "to be honest I am tired. Remember about the centre for children with special needs that I run with a business partner?" Bella nods. "Well, we had to make the decision to close it down."

She looks surprised. "Why? What happened?", she asks.

"There have been some changes in terms of the financial situation", I tell her. "The government cut down on the budget for therapies and special education resources. It became very difficult for us to keep it open."

"Oh... I'm so sorry...", she responds. "I had no idea."

"Thank you, Bella. As you can understand, there are a million things to do: inform everyone and explain the situation, pack up all the stuff, taking care of bureaucratic things... This is why I am not only tired but going through a process of grief."

"I can only imagine!", she replies.

I can feel my eyes are filling with tears which I hold back. I realise that this young woman had the courage to open up her concern about me, her therapist. I don't want to make her feel guilty or awkward for expressing her concerns. But I now have to attune to her needs and take care of our therapeutic relationship. After all, the communication processes that take place in a therapy session give rise to the reflective practitioner (Schön 1983), who reflects during acting and at the same time this ongoing reflection shapes the therapeutic practice (Juhl 2014). This is a perfect moment to "relate therapeutically" with my client (Flaskas 2016, p.149), which means understand my client's experience, use it therapeutically and reorganise myself in terms of relating with her and within myself.

I take another deep breath and let the air come out slowly. I feel gratitude for the meditation and yoga classes I attend. Mindful breathing and attunement to my bodily feelings are always useful in moments like these.

"Bella", I start slowly, "thank you for asking about how I am doing. It really means a lot to me. But as your therapist, I am concerned with what went on within you, when you asked me. What is it that you thought, can you tell me?", I ask gently. I feel focused now, being in the comfortable position of the caretaker.

"Well", she starts, "you seemed more quiet than usual today. Don't get me wrong, I don't mean that you didn't talk or that you didn't help me", she adds quickly, being careful not to offend me. I nod to indicate I understand and prompt her to continue. "But you were less lively today. And that made me wonder if everything is alright."

Good, I find myself thinking with relief. At least she doesn't think I am no longer helpful. 
"What was it like for you, when you hear me telling you about me being tired and what is going on with me?", I ask.

"It made me feel more connected to you, actually", she responds. "You know, there was a moment that I thought that maybe what I was saying was boring and of no interest to you", she confides.

Wow, I think, here is an example of the client taking personally what happens with her therapist... This is truly the importance of dialogue, especially in therapy! Imagine if she hadn't inquired about it... She would have gone home feeling unheard and unappreciated...

Dialogical processes are primarily a relational activity; conversational interactions involve coming into contact with another being and exploring ways of relating to one another (Shotter 2014). Ideas like these are in my mind every time I meet a client in therapy, where dialogue is an essential part of the process.

"But then, hearing you talking about what you have been going through, I guess, made me see you as more human", she continues, interrupting my thoughts.

Hmmm... I am thinking, this is what Rober (2011) means when he wrote that therapists are to be seen "as a complete human being in relation to the client" (p.237).

Even at a situation like this I feel more confident, when I am able to relate things I have read in theory with practice. It makes sense to me and I have the feeling that I am on the right track!

"Thank you for telling me, Bella", I say. "It's really important to me that you are able to articulate your thoughts and feelings in this room, in this relational space between us, without worrying how I will respond. After all", I add with a smile, "our relationship is strong enough to hold anything that comes up, right?"

"Right", she says smiling back.

We stand up and I give her a hug.

"I'll see you next week."

Fortunately, I have finished work for the day, so I have some time for myself to reflect on the experience with Bella, to create a reflective space for myself (Rober 2010, p.159). Systemic psychotherapists view the process of therapy as a dialogic activity and strive to find ways to explore how dialogue shapes the therapeutic interaction (Seikkula, Laitila \& Rober 2012). Apart from the outer dialogue, however, the therapist brings in the session not only her professional self, but also the voices of her personal selves, with her inner voices containing different experiences (Seikkula et al. 2012). Therefore, the therapist's inner dialogue, what I experience, feel and think (Rober 2010), create the relational space within the therapist, which plays an important role in the therapeutic relationship.

All these years in my practice as systemic therapist, I am particularly interested in the therapeutic relationship and I was fascinated by how "the relational aspects of the therapeutic interchange account for a more significant amount of change than skills or techniques" (Vetere \& Dowling 2005, p.64). I decided to develop a research study plan, in order to capture the complexity of the microprocesses in the therapy room. As a doctoral researcher, my inquiry focuses on exploring the relational space in the conversation that emerges between therapist and client, as well as within the therapist. Researching psychotherapy is an open-ended, non-linear process, where research informs practice 
and practice informs research (Strong, Busch \& Couture 2008). Consequently, I decided to research my own practice and my clients are joining me in collaborative dialogue, playing an active role in the research. My inquiry then lies in the field of practitioner research, which emphasises the process of doing research, the context within which the inquiry is situated, as well as the meaning and understanding of how experience is created (Yilmaz 2013).

In my everyday practice, as well as in my research - where in both cases I focus on the relational space in therapy - I use autoethnography. Autoethnography is "an autobiographical genre of writing and research that displays multiple layers of consciousness" (Ellis 2004, p.37). Autoethnographic writing helps bridging the gap between research and practice, as it encourages practitioner researchers to write from within practice in the first person. Autoethnographic writing also goes beyond writing about the self and aims at enabling previously silent voices to be heard (Denshire 2014). Through my reflective notes, my reflective diary and my stories, I try to capture the vivid experience of the psychotherapy process and invoke a sense of wonder. In these stories, as in the story in the beginning of this paper, the focus is not on the therapy techniques, nor on the client's difficulties. Instead, the relational conversation between my client and myself, as well as my inner dialogue and thoughts and feelings play a prominent role. Stories may have a fictional element, but they allow me to better portray real events and focus on my lived experience (Grant 2010). I look at what I am doing in a different lens. Autoethnographic stories require readers "to think with stories than about them" (Grant 2010, p.114).

In a situation like the one described in this story, another therapist might respond differently. For instance, she might try to reassure the client that everything is fine and that there is no reason for her to be concerned. Someone else might acknowledge that she is a bit tired, but not giving any details on the situation that she is going through. The way I see it, provided that I am careful not to make the therapy session about me, anything less than the truth felt like lying to my client as well as to myself. Despite of my emotional reactions -or maybe because of them? I use myself in a professional way, similarly as Seikkula, Karvonen, Kykyri, Kaartinen and Penttonen (2015) showed how practitioners can integrate their bodily reactions in the therapeutic dialogue. My professional self manages the uncertainty of the situation and focuses on the dialogue with my client, thus trying to enrich the therapeutic experience for her.

As most therapists, in the course of my career I stand on the shoulders of giants, who opened the way before me and influenced the way I practise. Jaakko Seikkula and his team in Finland started a psychosocial approach in their work with psychiatric patients, called Open Dialogue (Seikkula et al. 2012; Seikkula et al. 2015; Olson 2015), which includes patients and their family in the decisions about therapy. In line with this thinking, I consider my clients as co-participants in the process of change and collaborate during the therapy process. I am also particularly influenced by the work of Peter Rober $(1999,2010,2011)$ on the way the therapist brings her inner voices in the therapy room and how these inner voices become a powerful part of the dialogue. The way I see it, this process also includes, but is not limited to, the therapist's self-disclosure and transparency. In addition, I am influenced by the writings of John Shotter, which I incorporate in my work as a therapist. Shotter (2011) talked about relating with clients from a "withness-thinking" position, "that involves coming into living contact with an other's living being" (p.214), and this interaction might create new possibilities to emerge in the therapy session.

All these theoretical underpinnings shaped the way I interact with my clients and in this particular story with my client, Bella. As I mention in the story, I find it useful to connect theory with practice, in order to extend my thinking about my work. Using collaborative dialogue with my clients, as well as 
taking into account the voices of my different selves is an essential part in the way I practise psychotherapy. My clients and I are interconnected in the therapeutic relationship as "multi-beings" (Sermijn \& Gergen 2017, p.59), with various aspects of our lives entering the relational space in therapy. I remind myself that we are interconnected, as Sermijn and Gergen (2017) stated:

"All a client says and does in the therapeutic room, but also everything a therapist says and does, has to be understood not only in terms of their particular relationship, but in terms of what they both carry into the room as potentials, along with the way they are related to other persons, including the communities and traditions of which they are a part." (p.58)

People in therapy raise their real-life concerns, which often include social, political and ecological aspects. In this particular case, the therapeutic context was an individual session in private practice in Greece, a country that faces a social, economic and political crisis for many years. However, the situation described in this therapeutic encounter might well be familiar to therapists and clients elsewhere. By considering our clients and ourselves as "multi-beings" (Sermijn \& Gergen 2017, p.59) and by bringing our different selves in the therapy room we can think of therapy in a broader sociopolitical lens. From my point of view, at some point in the session I felt it as a personal failure. At the same time, I also saw it as a result of the economic crisis and of complex political and financial situations not only in Greece, but also worldwide, with equally complex socio-political consequences. It is a worrying and upsetting phenomenon and as a result my tiredness and grief is showing to my clients. Even if I tried to hide it, I can't pretend that it is not happening. As Bella mentioned, this situation of unsettling times helped her see me as more human and made us feel more connected to each other.

In this context, systemic therapists can benefit from the ideas that new materialist theorists and writers bring. In an era where the social, the political, the economical and the personal become an entangled network, therapists need to take into account the interconnectedness of these systems. As we understand that "humans are larger than a biological entity" (Braidotti 2013, p.8), the way we interact with each other changes as well. I am reminded of Barad (2007), as she writes that bodies are "being-of-the-world", rather than "being-in-the-world" (p.160). As therapists, therefore, we need to listen and respond differently to our clients and to our inner selves, not as individual entities but as relational bodies, which are part of the world. Being part of the world also means being part of our stories, stories that include our selves, others, human and the more-than-human world. Our stories matter, because we need to find meaning in this complex multi-systemic world. Stories help us to "gather up the complexities and keep the edges open and greedy for surprising new and old connections" (Haraway 2015, p.160). In my work as a therapist and as a practitioner researcher, I am using the work of new materialist theorists like Haraway, Barad, Braidotti and Pillow and incorporate it into my stories, in order to create new understandings of the interconnections that happen in -and out of - the therapy room.

This is a story with a good therapeutic outcome, in part because of a good therapeutic relationship. Not all stories are like that. The decision of when and how therapists respond to questions about themselves carries dangers, as well as opens up new possibilities in the therapy session. The client might perceive therapist's self-disclosure and transparency as either helpful or unhelpful (Roberts 2005). Especially when it comes to matters of the therapist's health and well-being, the client might feel protective of her therapist, watching to see if she is okay. Managing our clients' concerns about us and being aware of our clients' needs is our responsibility as therapists. Despite the dangers, however, my perspective on the therapist's self-disclosure and transparency is that it keeps open 
several possibilities in therapy, including bringing more of the client in the therapy room. Often change happens, when different visions, both the client's and the therapist's vision, enter explicitly into the therapeutic dialogue. In the words of Paolo Bertrando and Teresa Arcelloni (2006),

"...therapists and clients bring their own respective ways of framing their worlds to the conversation. Thus therapy is an encounter of frames, the one brought by the therapist and the one brought by the client, because all human beings live in a world made predictable by the rules defined by a frame, but creativity and novelty may emerge only by going outside of the known frames." (p.377)

This story from practice is more than the therapeutic dialogue, more than the therapist's selfdisclosure and transparency. It's also about reflexivity. As Anderson (2006) states, reflexivity "entails self-conscious introspection guided by a desire to better understand both self and others through examining one's actions and perceptions in reference to and dialogue with those of others" (p.382). In this context, I am being reflexive - both self-reflexive, as I share my experience and include myself in the process, and relationally reflexive, as I take into account my client's experience of therapy and how she perceives me. This story also reveals how something different emerges, something that disrupts the familiar and challenges the traditional way therapy is done (Pillow 2003). When we are relationally engaged with clients, we step away from a priori notions of how a "good" therapist "should" respond to her client and which way therapy "should" go (Sermijn \& Gergen 2017). As the therapy process unfolds, in following sessions this incident might again enter the therapy room and transform the relational space between Bella and myself, since the interactions between people are interconnected and reconfigure their relationships (Hein 2016).

The process of researching my practice is a messy endeavour and comprises ethical complexities (Helps 2017). As a practitioner researcher, my role is complex and in my inquiry, I make every effort to include my participants' voices in an ethical and reflexive manner (Lester \& Anders 2018). I am constantly asking myself ethical questions: Are my clients' voices acknowledged in the research? How do I speak meaningfully and ethically about the relational space between my clients and myself? Do I approach the research process with reflexivity and flexibility? How can I present my findings in a way that social justice concerns are addressed? How can I share my stories from a relational ethics point of view? I am aware that by researching my own practice, I also affect the way I practise and I am affected by what I notice, feel and think. However, being an insider researcher is not something to be avoided; on the contrary, it is important to be clear on the roles I take, as a therapist as well as a researcher, and be transparent about these roles (Helps 2017).

Therapists might have the intuitive knowledge from practising psychotherapy that sharing their experience with their clients might help them explore more of themselves. In writing this paper, as in my role as a practitioner researcher, I want to bring another perspective as well. I build on the ideas of combining my inner dialogue and the collaborative dialogue with my clients, and reflect on what this combination means for therapists. I feel compelled to write about this. As Grant (2016, p.201) encourages practitioners to "increase our sensitivities around what we talk", my aim is to break the silence and allow practitioners to extend their thinking and talk about the things that we don't normally talk about in our profession. As an example, in this paper, I name the economic crisis and its impact on society, on psychotherapy and on me as a systemic therapist struggling to fill a gap in resources. In a similar way, I aim to encourage therapists to step out of their comfort zone and experience the relational space in therapy from a different perspective. As Struthers (2012) mentioned in his thesis, "Sharing my vulnerability and disclosing aspects of self that I would usually avoid sharing, was in itself a challenge." For me the challenge was both sharing a vulnerable part of myself with my 
client, as well as sharing this story with colleagues and readers. In both these circumstances, I was anxious of how the "other" would take in my words. However, I believe that sharing my experience with others might help them explore and develop the way they experience things, including the way therapy is done.

Clients come to therapy to tell their story, and this act requires courage. We, as therapists, have the enormous privilege of hearing our clients' stories and as a result we feel connected to them. Through these stories, both my clients and me - as a therapist and as a person- learn more deeply about ourselves and of being human (Orbach 2016). By paying attention to the way both parts of the conversation interconnect with each other, new possibilities emerge in the therapeutic space. As Simon (2014) states, "We work with people so they can hear what it is they want to say and find ways of saying it to themselves, to us and to others who matter." (p.14)

Despite my years of practice, I am still amazed at the living relational energy of the therapeutic relationship, particularly the emotional connection between client and therapist. It is not uncommon for clients to voice their concerns, particularly about me, their therapist. The therapeutic relationship is of particular importance and clients need to be reassured that the person who is assigned the role of the helper will be there to help them overcome their difficulties. Seen from this perspective, I am not surprised that Bella inquired about me being tired at this particular occasion. After all, Bella is an insightful young woman, who is particularly adept at picking up others' feelings. I am surprised by myself, however, that I had the impression that I could successfully put aside the feelings that are associated with my recent professional loss and keep them out of sight of the clients I am working with. Within the systemic framework, the therapist is part of the system and is transformed by the therapy process, as does the client (Minuchin, Reiter \& Borda 2014). Rather than trying to ignore my contribution to the relational space in therapy, I believe it is best to acknowledge what I bring in the therapy room and include my whole self in the therapy process. Systemic therapists should be aware of "the importance of being a self-observing therapist and the ways in which our life experiences help shape our therapeutic strengths and blind spots" (Minuchin et al. 2014, p.158).

I need to constantly remind myself that our work as therapists involves teaching our clients to keep an eye on their emotions and, if we are doing a good job, then clients are able to pick up on our own emotions as well. This is the craft of psychotherapy.

\section{References}

Anderson, Harlene (2005). Myths About “Not-Knowing”. Family Process, 44, 4, 497-504.

Anderson, Leon (2006). Analytic Autoethnography. Journal of Contemporary Ethnography, 35, 4, 373-395.

Barad, Karen (2007). Meeting the Universe Halfway. London: Duke University Press.

Bertrando, Paolo \& Arcelloni, Teresa (2006). Hypotheses are dialogues: Sharing hypotheses with clients. Journal of Family Therapy, 28, 4, 370-387.

Braidotti, Rosi (2013). Posthuman Humanities. European Educational Research Journal, 12, 1, 1-19.

Denshire, Sally (2014). On auto-ethnography. Current Sociology, 62, 6, 831-850.

Ellis, Carolyn (2004). The Ethnographic I: A Methodological Novel About Autoethnography. Walnut Creek, CA: Altamira Press. 
Etherington, Kim (2004). Becoming a Reflexive Researcher: Using Our Selves in Research. London: Jessica Kingsley Publishers.

Flaskas, Carmel (2016). Relating therapeutically in family therapy: Pragmatics and intangibles. Journal of Family Therapy, 38, 1, 149-167.

Grant, Alec (2010). Writing the reflexive self: An autoethnography of alcoholism and the impact of psychotherapy culture. Journal of Psychiatric and Mental Health Nursing, 17, 7, 577-582.

Grant, Alec (2016). Living my narrative: storying dishonesty and deception in mental health nursing. Nursing Philosophy, 17, 3, 194-201.

Haraway, Donna (2015). Anthropocene, Capitalocene, Plantationocene, Chthulucene: Making Kin. Environmental Humanities, 6, 159-165.

Hein, Serge F. (2016). The New Materialism in Qualitative Inquiry: How Compatible Are the Philosophies of Barad and Deleuze? Cultural Studies - Critical Methodologies, 16, 2, 132-140.

Helps, Sarah (2017). The ethics of researching one's own practice. Journal of Family Therapy, 39, 3, 348-365.

Hendrix, Harville \& Hunt, Helen LaKelly (2017). The Space Between: The point of connection. USA: Clovercroft Publishing.

Juhl, Andreas Granhof (2014). Pragmatic Inquiry: A research method for knowledge creation in organisations. In Systemic Inquiry: Innovations in Reflexive Practice Research, Simon, Gail \& Chard, Alex (Eds.). Farnhill: Everything is Connected Press.

Lester, Jessica Nina \& Anders, Allison Daniel (2018). Engaging Ethics in Postcritical Ethnography: Troubling Transparency, Trustworthiness, and Advocacy. Forum: Qualitative Social Research, 19, 3, Art. 4.

Minuchin, Salvador; Reiter, Michael D. \& Borda, Charmaine (2014). The Craft of Family Therapy. New York: Routledge.

Oliver, Christine (2014). Using CMM to Define Systemic Reflexivity as a Research Position. In Systemic Inquiry: Innovations in Reflexive Practice Research, Simon, Gail \& Chard, Alex (Eds.). Farnhill: Everything is Connected Press.

Olson, Mary (2015). An Auto-Ethnographic Study of "Open Dialogue": The Illumination of Snow. Family Process, 54, 4, 716-729.

Orbach, Susie (2016). In Therapy: How conversations with psychotherapists really work. UK: Profile Books Ltd.

Pillow, Wanda (2003). Confession, catharsis, or cure? Rethinking the uses of reflexivity as methodological power in qualitative research. International Journal of Qualitative Studies in Education, 16, 2, 175-196. https://doi.org/10.1080/0951839032000060635.

Rober, Peter (1999). The therapist's inner conversation in family therapy practice: Some ideas about the self of the therapist, therapeutic impasse, and the process of reflection. Family Process, 38, 2, 209-228.

Rober, Peter (2010). The interacting-reflecting training exercise: Addressing the therapist's inner conversation in family therapy training. Journal of Marital and Family Therapy, 36, 2, 158-170.

Rober, Peter (2011). The therapist's experiencing in family therapy practice. Journal of Family Therapy, 33, 3, 233-255.

Roberts, Janine (2005). Transparency and Self-Disclosure in Family Therapy: Dangers and Possibilities. Family Process, 44, 1, 45-63.

Schön, Donald A. (1983). The Reflective Practitioner. How professionals think in action. UK: Ashgate Publishing Ltd. 
Seikkula, Jaakko; Laitila, Aarno \& Rober, Peter (2012). Making Sense of Multi-Actor Dialogues in Family Therapy and Network Meeting. Journal of Marital and Family Therapy, 38, 4, 667-687.

Seikkula, Jaakko; Karvonen, Anu; Kykyri, Virpi-Liisa; Kaartinen, Jukka \& Penttonen, Markku (2015). The Embodied Attunement of Therapists and a Couple within Dialogical Psychotherapy: An Introduction to the Relational Mind Research Project. Family Process, 54, 4, 703-715.

Sermijn, Jasmina \& Gergen, Kenneth J. (2017). Spread the Wings of your Therapeutic Potential: A Reflecting Process with Ken Gergen. International Journal of Collaborative-Dialogic Practice, 8, 1, 57-68.

Simon, Gail (2014). Systemic Inquiry as a form of Qualitative Inquiry. In Systemic Inquiry: Innovations in Reflexive Practice Research, Simon, Gail \& Chard, Alex (Eds.). Farnhill: Everything is Connected Press.

Shotter, John (2011). Getting It: Withness-Thinking and the Dialogical...in practice. New York: The Hampton Press.

Shotter, John (2014). Agential realism, social constructionism, and our living relations to our surroundings: Sensing similarities rather than seeing patterns. Theory and Psychology, 24, 3, 305-325.

Strong, Tom; Busch, Robbie \& Couture, Shari (2008). Conversational evidence in therapeutic dialogue. Journal of Marital and Family Therapy, 34, 3, 388-405.

Struthers, John (2012). Analytic autoethnography: A tool to inform the lecturer's use of self when teaching mental health nursing? Unpublished thesis, Department of Educational Research, Lancaster University. Available online at: http://eprints.lancs.ac.uk/62512/1/Struthers_John_Final_2013_Feb.pdf

Vetere, Arlene \& Dowling, Emilia (Eds.) (2005). Narrative Therapies with children and their families. London: Routledge.

Yilmaz, Kaya (2013). Comparison of Quantitative and Qualitative Research Traditions: epistemological, theoretical, and methodological differences. European Journal of Education, 48, 2, 311-325.

\section{Author}

Marilena Karamatsouki is a systemic psychotherapist in private practice based in Athens, Greece. She is also currently a candidate for the Professional Doctorate in Systemic Practice at the University of Bedfordshire.

Email: marilena.karamatsouki@study.beds.ac.uk

\section{Citation}

Karamatsouki, Marilena (2019). Therapy in Unsettling Times. Murmurations: Journal of Transformative Systemic Practice, 2, 2, 29-38. https://doi.org/10.28963/2.2.4 